Special Issue of the 6th International Congress \& Exhibition (APMAS2016), Maslak, Istanbul, Turkey, June 1-3, 2016

\title{
pH Dependent Degradation and Characterization of Geopolymer Structures Derived from Fly Ash
}

\begin{abstract}
K. ŞAHBUDAK*
Cumhuriyet University, Department of Metallurgical and Materials Engineering 58140 Sivas, Turkey

Geopolymer structures are a relatively new family of un-fired ceramics that are produced by alkaline slurry of mixed alumina silicate-based materials. One of the most abundant geopolymer-forming powders is the fly ash. Fly ash is a waste product of thermic coal plants, which produce electricity by coal burning. Fly ashes contain mostly $\mathrm{Ca}, \mathrm{Al}, \mathrm{Si}$ and $\mathrm{Fe}$ oxide mixtures and compounds formed during the burning process, followed by sedimentation. The standardization is made by $\mathrm{SiO}_{2}$ content. Class $\mathrm{C}$ ash has low silica content $(<50$ wt.\%) and class $\mathrm{F}$ ash has a higher silica content $(>50$ wt.\%). The fly ash, studied in this work, was obtained from Kangal Coal Plant. The $\mathrm{NaOH}$ was used as the geopolymer binder and curing was performed at $80 \%$ relative humidity, at $40{ }^{\circ} \mathrm{C}$ in sealed plastic molds. The obtained cylinders were aged for one week before releasing from molds. pH dependent degradation was used to determine the ionic exchange of geopolymers into the solution. Afterwards, XRD and SEM were done to detect the structural changes of geopolymers.
\end{abstract}

DOI: 10.12693/APhysPolA.131.379

PACS/topics: Geopolymer, alkaline, pH, SEM, XRD

\section{Introduction}

Geopolymers are amorphous-to-semi-crystalline equivalent of certain zeolitic materials with excellent properties [1-3]. Besides metakaolin, some waste materials such as fly ash can also be used for the synthesis of the geopolymers $[3,4]$. Generally, alkali metal (Na or $\mathrm{K}$ ) silicate or hydroxide is used as an activator for synthesis of the metakaolin-based or fly ash-based geopolymers.

Portland cements, but also the composition of the calcium silicate hydrate $(\mathrm{C}-\mathrm{S}-\mathrm{H})$ gel comes from hydration. On the other hand, the choice of $\mathrm{w} / \mathrm{c}$ ratio impacts the $\mathrm{Ca} / \mathrm{Si}$ ratio and hydrate amount of the $\mathrm{C}-\mathrm{S}-\mathrm{H}$ gel $[4-6]$. Activation takes place as a hydration chemical process with aluminosilicate structure. Ashes of natural or industrial origin could be turned into cementitious-like infrastructures when subjected to a highly alkaline solution, such as $\mathrm{NaOH}[5-7]$. The spalling of regular concrete comes up in fire, leading a rapid layered loss of concrete cover. It potentially leads to the subjection of the main additives [8].

Depending on the reaction parameters, three types of geopolymers are considered: poly(sialate) (-Si-O-Al-O- $)$, poly (sialate-siloxo) $(-\mathrm{Si}-\mathrm{O}-\mathrm{Al}-\mathrm{O}-\mathrm{Si}-\mathrm{O}-$ ) and poly(sialate-disiloxo), (-Si-O-Al-O-Si-O-S-O-), in which the ratios of $\mathrm{Si}: \mathrm{Al}$ are 1,2 and 3, respectively $[6,7,9]$. The presence of aluminum in an aluminosilicate gel is very important from the standpoint of hydrolytic stability of the gel in an aqueous environment. The factors that increase the dissolution of fly ash are of primary importance for the hydrolytic stability of fly ash-based geopolymers [9]. Previous studies have shown that $\mathrm{pH}$ of the geopolymers when subjected to distilled

*e-mail: kemalsahbudak@gmail.com water was about 10-11.2. Since the hydroxylation is so strong in geopolymer structure, even the acid rain was able to decrease the $\mathrm{pH}$ down to only 8.4-9.5.

This study attempts an effort to evaluate the structure of geopolymers made of class $\mathrm{C}$ fly ash with high $\mathrm{Ca}$ content and $\mathrm{NaOH}$ binder/alkaline activator. Moreover, the $\mathrm{pH}$ of geopolymers with respect to time was studied and real time effects were shown by SEM (FEG, Mira $3 \mathrm{XMU}^{\circledR}, \mathrm{TESCAN}, \mathrm{CZ}$ ) and macro photos, respectively.

\section{Materials and methods}

The geopolymer structure was formed from powders obtained from Kangal Coal Plant Co. (Kangal, SIVAS). Kangal region was employed in coal production for over 30 years. Here coal was burnt in thermic plants and residue was deposited in a nearby valley and eventually has formed a huge hill. The chemical composition of fly ash is given in Table I.

TABLE I

Chemical composition of ground fly ash.

\begin{tabular}{c|c|c|c|c|c|c|c|c|c|c}
\hline \hline Compon. & $\mathrm{SiO}_{2}$ & $\mathrm{Al}_{2} \mathrm{O}_{3}$ & $\mathrm{Fe}_{2} \mathrm{O}_{3}$ & $\mathrm{CaO}$ & $\mathrm{MgO}$ & $\mathrm{Na}_{2} \mathrm{O}$ & $\mathrm{K}_{2} \mathrm{O}$ & $\mathrm{SO}_{3}$ & $\mathrm{LOI}$ \\
\hline wt.\% & 19.3 & 15.5 & 8.3 & 38.5 & 2.9 & 3.5 & 2.8 & 4.1 & 5.1
\end{tabular}

Due to the high Ca content in the residue, the synthetic hill is of a rocky structure, as a result of rains and wind. Inhaling this ash should be avoided due to present nanoscale dust. As it has been in our experiment, the water content was between $20 \mathrm{wt} . \%$ and $25 \mathrm{wt} . \%$ of dry basis. The fly ash was the only powder used for geopolymer formation, $1 \mathrm{M}$ and $3 \mathrm{M}$ of $\mathrm{NaOH}$ was added as binder, and water was used as the solvent for hydration. Relative humidity of $80 \%$ was applied to all samples. The curing temperature in plastic molds, with plastic lids on, was $40^{\circ} \mathrm{C}$. The dimensions of silicon plastic bar-shaped molds were $150 \times 10 \times 10 \mathrm{~mm}^{3}$. The curing was performed for one week, to complete the gel-hydration process. 
The molds were released after this period and samples were matured for one month at room temperature, at a relative humidity of $50 \%$, prior to characterization by SEM and XRD (Rigaku D Max-II, Japan) for morphology and phases, respectively and prior to $\mathrm{pH}$ tests.

The fly ash was reburnt again at $800^{\circ} \mathrm{C}$ for $2 \mathrm{~h}$ in an electric furnace (Protherm $1300^{\circ} \mathrm{C}$, Turkey, K-type thermocouple) in static air atmosphere for the final removal of carbon, and dry ground for one day in a $250 \mathrm{ml}$ Nalgene bottle with alumina balls of $6 \mathrm{~mm}$ in diameter. Ball to powder ratio was kept at 20:1 in all experiments. The shape of powder grain was evaluated by means of flowing ability to be more like pseudo-spherical. As alkaline activator/binder, $\mathrm{NaOH}$ pellets were chosen due to low cost and easiness of purchasing in analytical grade (Sigma-Aldrich GmbH, Germany). Distilled water was used in all experiments as the solvent. In geopolymer formation $1 \mathrm{M}$ and $3 \mathrm{M}$ of $\mathrm{NaOH}$ were used to produce two types of structures and for $\mathrm{pH}$ dependency features.

\section{Results and discussion}

The high Ca content in the ash can be seen from XRD pattern, taken before the calcination (Fig. 1). XRD pattern illustrates presence of such calcined phases as Augite and Diopside. The formation of Meixnerite and Alunite is also evident, which is due to release of water by the plant, just after burning, onto the residues, to prevent dust formation. Since the hydrated phases exist, the water demand decreases in geopolymer formation down to $20 \mathrm{wt} \%$.

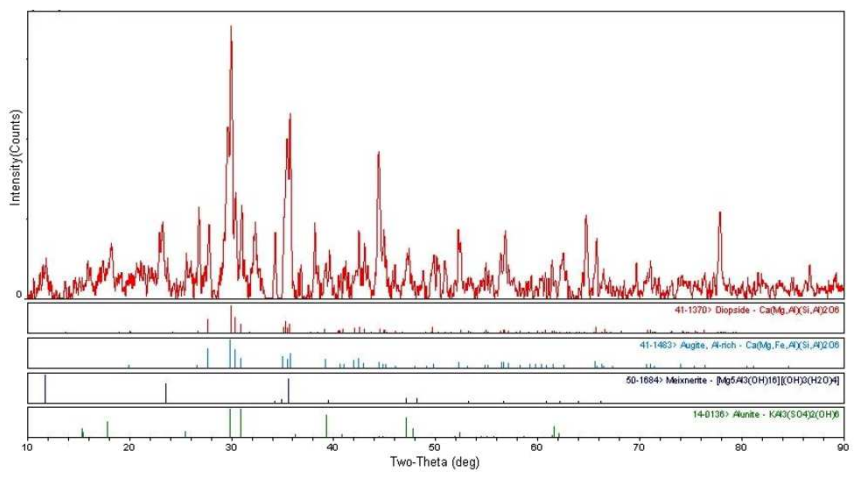

Fig. 1. XRD pattern of Kangal fly ash before calcination and geopolymerization.

When geopolymerization was completed after one week at $40^{\circ} \mathrm{C}$ and $80 \%$ relative humidity, the products were ground after 30 days of maturing. Another XRD pattern, as shown in Fig. 2a was taken to evaluate the gel formation for geopolymerization. The pattern shows that the aluminasilicate phases at $18^{\circ}, 20.5^{\circ}, 26^{\circ}$ and $34^{\circ}$ $(2 \theta)$ have occurred with low crystallinity, due to high background level and the fact that formation of phases was not complete. Besides, Ca-Al-Si-OH phases at $13^{\circ}$, $23.5^{\circ}, 25^{\circ}, 27^{\circ}$ and $32^{\circ}(2 \theta)$ are visible, with small peaks accompanying the main peaks. The low crystallinity is also evident due to non-formed low intensity of peaks and large peak widths. As seen from Fig. 2b, the $1 \mathrm{M}$ $\mathrm{NaOH}$ activation makes the surface less smooth, while $3 \mathrm{M} \mathrm{NaOH}$-activated product (Fig. 2c) has a smother surface, which leads to small and closed pores. In such samples almost no water absorption was observed. This could be attributed to the formation of a better gel of geopolymer which produces closed pores and reacted smooth surfaces, which do not let the water in.

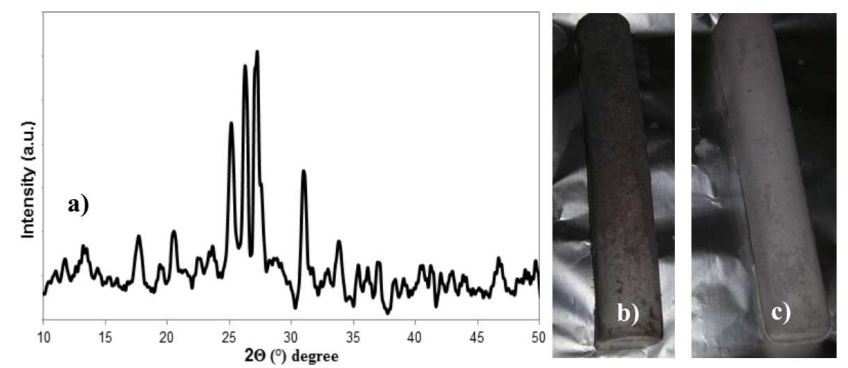

Fig. 2. (a) XRD pattern of geopolymerized (3 M $\mathrm{NaOH}$ ) fly-ash-based product, (b) macro photo of $1 \mathrm{M}$ $\mathrm{NaOH}$-activated products, (c) macro photo of $3 \mathrm{M}$ $\mathrm{NaOH}$-activated product, after mold release and maturing for 30 days.

The geopolymer formation was evaluated by SEM (Fig. 3) for both surface features and compositional imaging, respectively. $1 \mathrm{M} \mathrm{NaOH}$-activated geopolymer is illustrated in Fig. 3. The fractured surface has open pores and low crystalline structure is seen. The pores were distributed and formation of small ettringite phase is seen, which is due to low hydration by lower molarity $\mathrm{NaOH}$ activation. Figure $3 \mathrm{a}$ shows the formation of very small ettringite phase in the middle of image, as rod-like particles, grown from the matrix. Figure $3 \mathrm{~b}$ shows the compositional imaging and in the middle of image, the rod-like phase has larger lattice parameter, seen as whiter phase which corresponds to $\mathrm{Ca}-\mathrm{Al}-\mathrm{Si}-\mathrm{Mg}-\mathrm{O}$ related phases in backscattered electron imaging, as confirmed by XRD pattern.
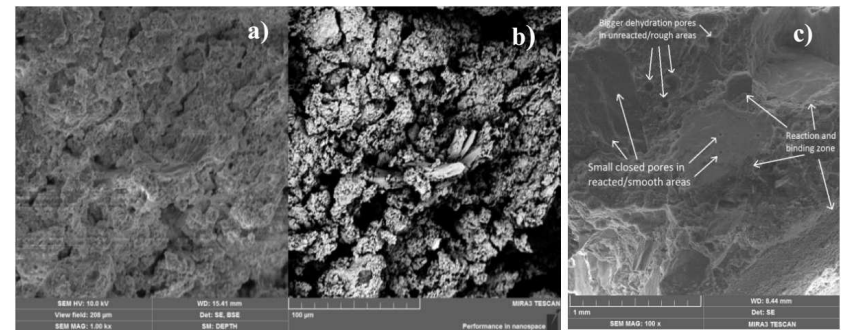

Fig. 3. SEM (a) SE, (b) BSE images of geopolymerized product with $1 \mathrm{M} \mathrm{NaOH}$ activation, (c) $3 \mathrm{M} \mathrm{NaOH}$ activation (arrows indicate the corresponding regions).

The $\mathrm{pH}$ dependency tests were evaluated in distilled water and the increase in $\mathrm{pH}$ was recorded in time for one week $(168 \mathrm{~h})$, for each product. The increasing molarity 
of $\mathrm{NaOH}$ to $3 \mathrm{M}$, enhances the geopolymerization by increasing the surface quality via decreasing the number of pores. The decrease of number of pores leads to low water absorption and thus the $\mathrm{pH}$ values increase slowly, as seen in Fig. 4 (inset).

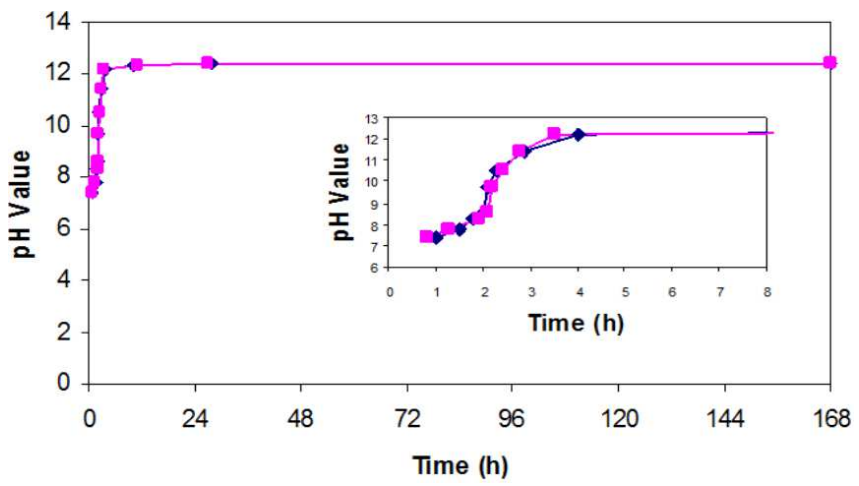

Fig. 4. pH dependency tests of two geopolymerized products, continued for one week.

The open pores permit the water inside the structure faster, leading to spalling of outer surface due to hydration and lack of geopolymerization. Increased molarity of $\mathrm{NaOH}$ (from $1 \mathrm{M}$ to $3 \mathrm{M}$ ) had increased the surface quality and higher amount of binding was achieved.
The water was taken slowly into the structure due to smaller and closed pores. Due to the completion of geopolymerization, the binder phase stays with structure instead of spalling. No spalling was seen in $3 \mathrm{M}$ activated geopolymer sample, as $\mathrm{pH}$ tests show.

\section{References}

[1] Hu Mingyu, Zhu Xiaomin, Long Fumei, Cement Concrete Comp. 31, 762 (2009).

[2] K. Arbi, A. Palomo, A. Fernández-Jiménez, Ceram. Int. 39, 9237 (2013).

[3] E.M. Gartner, D.E. Macphee, Cement Concrete Res. 41, 736 (2011).

[4] C. Ruiz-Santaquiteria, J. Skibsted, A. FernándezJiménez, A. Palomo, Cement Concrete Res. 42, 1242 (2012).

[5] C. Chen, W. Gong, W. Lutze, I.L. Pegg, J. Mater. Sci. 46, 3073 (2011).

[6] P. Posi, C. Teerachanwit, C. Tanutong, S. Limkamoltip, S. Lertnimoolchai, V. Sata, P. Chindaprasirt, Mater. Des. 52, 580 (2013).

[7] P. Pranda, K. Prandov, V. Hlavacek, Fuel Proc. Technol. 61, 2111999.

[8] D.L.Y. Kong, J.G. Sanjayan, K. Sagoe-Crentsil, Cement Concrete Res. 37, 1583 (2007).

[9] A. Bagheri, A. Nazari, Mater. Des. 54, 483 (2014). 